\section{Climatic reconstruction}

Tree Rings and Climate. By H. C. Fritts. Pp. xii +567. (Academic: London and New York, 1977.) £16; \$35.

THIS is the first book to deal comprehensively with the relationships between tree-rings and climate, and their use to reconstruct past climates. By far the greatest volume of research in this field has been carried out in the United States and the majority stems from the Laboratory of Tree-Ring Research in Tucson, Arizona. Although tree-ring research has been carried out in the arid south-western United States and in Europe for over 50 years, it has been the development of a rigorous statistical approach, and the use of the newer multivariate techniques by Fritts and his colleagues at Tucson, that has transformed tree-ring studies from a dating technique to a climatic reconstruction science of world-wide application.

This book is thorough in its approach and assumes little previous knowledge. In particular, the author reviews the biology of tree growth from the molecular level through cellular to the whole tree and presents this account in a clear manner unchuttered with jargon. Some may feel that this aspect has been overplayed, as nearly 200 pages of the book are devoted to aspects of tree biology. Many scientists approaching dendroclimatology do so, however, from a non-biological background and would find the clear accounts in these early chapters most helpful. Following this biological introduction, the climate-growth relationships are examined and a series of models are proposed to explain a variety of observed relationships. There follows a rather brief account of the mechanics of tree-ring dating from sample collection, preparation and measurement to tests of reliability and the statistics used to describe tree-ring series. Included in this section is a mention of the techniques of timeseries analysis that have been applied to tree-ring series.

The following chapters, which contain the real meat of the book, deal with the calibration of ring-width with climate and the concept of the response function. In this area, where the mathematical manipulations are difficult, Fritts succeeds in introducing each new concept and provides plenty of examples to show its application. In particular, he justifies and explains the use of eigenvectors of climatic variables in the multiple regression with ring-widths. $\mathrm{He}$ works through a number of examples and offers some biological interpretations. This technique, which circumvents the problems caused by relationships between the variables, has so far been little used by other workers.

Although the response function of a single tree-ring series can be found and attempts made to interpret it in terms of growth models, it is seldom of any use for the reconstruction of past climate as the factors affecting growth are too complex. A factor such as high temperature may be found beneficial at some times of the year, and detrimental at others. Using several study sites, Fritts shows how multivariate techniques often allow valid reconstructions to be made.

The final chapters concentrate on examples of the more recent multivariate approaches-such as, reconstructions of lake levels, river flow, sea temperature, and even fish catches,

\section{Chemical history}

Chemists by Profession: The Origins of the Royal Institute of Chemistry. By Colin A. Russell with Noel G. Coley and Gerrylynn K. Roberts. Pp. x+342, 28 plates. (Open University Press, in association with The Royal Institute of Chemistry, 1977.) $£ 9.50$.

THE social history of science may seem a vague or obscure enterprise; but the attempt to discover what it felt like to be a chemist or physicist in the past cannot but be interesting, and is valuable because it casts light on that great majority of scientists who do not have a process, a genus or an equation named after them. This history of the Royal Institute of Chemistry, a body which is this year celebrating its centenary, is more than a benign tribute; it is a critical history, with particular emphasis on the gradual emergence of chemistry as a profession as well as a discipline. It is especially strong on the earliest years of the Institute (which did not become Royal until 1944), and indeed on the years before the Institute was founded-we do not get to the birth of the Institute until nearly half way through the book. This emphasis is completely justified by the authors, because unless one had understood what the position of chemists was before 1877 one would not understand the Institute and its problems, many of which have continued well beyond 1877 .

The authors trace chemistry back not only to alchemists but also to assayers and pharmacists; and the tension between academics, chiefly preoccupied with the increase of knowledge but also anxious to promote careers for their graduates, and the which are controlled by sea temperature. The last chapter gives in some detail the recent attempts by Fritts and his colleagues at pressure reconstructions using large numbers of tree-ring stations in the United States. This chapter also looks in detail at the various techniques of verification used to test the validity of the pressure reconstructions.

The book is well produced and clearly printed, and is remarkably free from minor errors. It should be of interest to all climatologists, and to a wide range of biologists, and its readable style compensates for its considerable length and detail. The explanations of multivariate techniques may well be of value to workers in entirely different fields.

Jon R. Pilcher

Jon R. Pilcher is Lecturer in Palaeoecology at Queen's University, Belfast, UK.

practical men, or practising chemists, has remained ever since. At the British Association, Section B devoted to chemistry dates back to 1835 ; while in 1841 both the Chemical Society-the first in the world, but many years after the Geological and Astronomical Societies-and the Pharmaceutical Society were founded. The Chemical Society was a learned society, run by academics; but with the rise of chemical industry, the invasion by science of industries like brewing, and the passing of laws against pollution, the industrial chemist and the consultant analyst appeared upon the scene in greater numbers, and demanded professional regulation.

On the one hand, there was pressure (especially from the academics) for high standards; and on the other, pressure to include and register all those working in the field of chemistry, many of whom could not pass examinations of honours degree standard. In the event, it was only in the last third of its century that the Institute took these wider responsibilities as its most pressing concern; in the earlier years its professional functions were narrower than they are now-when it has also merged with the learned society from which a hundred years ago it separated. This history does not answer all the questions that one might want to know; it is generous to previous historians, and also to participants in the history, and does not dilate overmuch upon money, patronage or feuds; but it provides a splendid account of its subject, which will interest not only historians but also scientists.

David Knight

David Knight is Senior Lecturer in History of Science at the University of Durham. He has recently published The Nature of Science (Deutsch, 1977). 